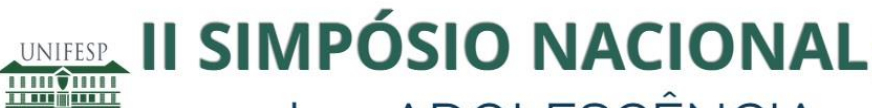 sobre ADOLESCÊNCIA: Vulnerabilidades, Protagonismos e Desafios
}

\section{Avaliação da depressão pós-parto e uso de substâncias em mulheres em situação de vulnerabilidade social na cidade de São Paulo}

\author{
Leila Regina da Silva Teixeira \\ Universidade Anhembi Morumbi \\ Adriana Scatena \\ Universidade Federal de São Paulo \\ Ricardo Abrantes do Amaral \\ Universidade Anhembi Morumbi \\ Universidade de São Paulo \\ André Luiz Monezi Andrade \\ Universidade Anhembi Morumbi \\ Universidade Federal de São Paulo
}

\section{Como citar:}

TEIXEIRA, Leila Regina da Silva et al. Avaliação da depressão pós-parto e uso de substâncias em mulheres em situação de vulnerabilidade social na cidade de São Paulo. In: II SIMPÓSIO NACIONAL SOBRE ADOLESCÊNCIA: VULNERABILIDADE, PROTAGONISMOS E DESAFIOS, 2. 2016, São Paulo. Anais...[S.I]: 2016. p. 57-58.

DOI: http://dx.doi.org/10.22388/2525-5894.2016.037

Introdução: a depressão pós-parto (DPP) é um transtorno mental caracterizado por humor depressivo em aproximadamente 20 a $25 \%$ das puérperas. A DPP possui uma etiologia multifatorial, o que envolve desde variáveis fisiológicas até psicossociais. Além disso, existem diversas evidências de que a DPP esteja relacionada com o uso de substâncias, embora esta relação ainda seja pouco estudada, especialmente em puérperas em situação de vulnerabilidade social.

Objetivos: avaliar a prevalência de DPP e possível associação com o uso de substâncias em mulheres que residiam provisoriamente no alojamento de um Hospital Maternidade da Cidade de São Paulo.

Métodos: 102 mulheres participaram do estudo e foram entrevistadas a partir de um questionário socioeconômico, composto por 13 perguntas específicas, além de dois questionários padronizados: Escala de Depressão Pós-Parto de Edimburg (EPDS) e Teste de Triagem do Envolvimento com Álcool, Cigarro e Outras Substâncias (ASSIST).

Resultados: aproximadamente $20 \%$ das puérperas foram classificadas com DPP, segundo o instrumento EPDS e destas observou-se maior consumo de álcool $(p<0,05)$ em relação aquelas que não apresentavam o transtorno. Além disso, as mulheres com DPP relataram histórico de violência familiar e falta de suporte psicossocial $(p<0,05)$ em relação ao outro grupo.

Conclusões: os dados encontrados neste trabalho referentes a prevalência de DPP estão alinhados com outros achados da literatura nacional. Além disso, a falta de suporte familiar e uso de substâncias parecem influenciar na etiologia da DPP, fortalecendo a hipótese de um determinismo multifatorial. 
Palavras-chave: Transtorno Depressivo. Transtornos Relacionados ao Uso de Substâncias. Período Pós-

Parto. Vulnerabilidade Social. 